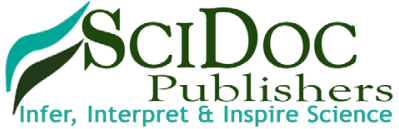

International Journal of Food Science, Nutrition and Dietetics (IJFS)

ISSN:2326-3350

\title{
A Study on the Prevalence of Obesity in Type II Diabetes Mellitus among Female Adults Aged 20-50 Years Attending Abha and Khamis Mushayat Diabetic Centres in Saudi Arabia
}

Research Article

Sachithananthan $\mathrm{V}^{*}$

Faculty of Public health, College of Applied Medical Sciences, King Khalid University, Abha, Saudi Arabia.

\section{Abstract}

Background: A sedentary lifestyle and prevalence of obesity are the key factors which lead to an increasing prevalence of Type II diabetes mellitus. There is strong evidence that modifiable risk factors such as obesity and physical inactivity are the main non-genetic determinants of the disease and could be modified.

Objectives: To determine the prevalence of obesity ( $\geq 30$ BMI - body mass index) among the selected subjects.

Subjects and Methods: A cross sectional study was adopted. Around 1000 female subjects aged 30-50 years, with Type II diabetes mellitus were selected randomly from Abha and Khamis Mushayat Diabetic care centers. The data were collected by questionnaire which included background information. Other physiological, biochemical and anthropometric parameters were measured using standard procedures. The statistical analysis was done on SPSS 20 platform.

Results: The socioeconomic background did not correlate with BMI and other selected anthropometric (waist and hip circumference) and biochemical parameters such as fasting and random blood sugar levels. With regards to the BMI status of the subjects, a majority of the subjects were in Grade I (31.1\%) and Grade II (29.8\%) obesity ranges indicating high prevalence rate of obesity in the diabetes mellitus subjects. Around $8.6 \%$ of the subjects had morbid obesity ( $\geq 40$ BMI). Totally the prevalence of obesity in the present study in type II diabetes mellitus subjects was $69.5 \%$.

Conclusion: Stressing on the importance of a balanced low glycemic diet and adequate physical activity through regular counseling of the diabetes subjects, to treat and prevent obesity is the need of the hour.

Keywords: Type II Diabetes Mellitus; Obesity; BMI; Blood Glucose Levels.

\section{Introduction}

Type II diabetes mellitus, formerly known as non-insulin dependent diabetes mellitus or adult onset diabetes is a metabolic disorder that results in hyperglycemia due to the body being ineffective at using the insulin it has produced, also known as insulin resistance and or being unable to produce enough insulin. In recent years, it has become apparent that many people with type II diabetes are able to manage diabetes through methods including physical activity and low carbohydrate diets, which means very low calorie diets and exercise [1].

A sedentary lifestyle and prevalence of obesity which are the main non-genetic determinants of the disease are the key factors which lead to an increasing prevalence of Type II diabetes mellitus. An interaction between a genetic predisposition and behavior and environmental factors leads to Type II diabetic mellitus [2].

In Saudi Arabia, 25.5\% of the urban population is diabetic in comparison with $19.5 \%$ in rural areas. There are also regional differences in the prevalence of type II diabetes, with the Northern $(27.9 \%)$ and Eastern $(26.4 \%)$ provinces experiencing greater rates than the Southern region $(18.2 \%)$, where a rural lifestyle is more common [3] and the population less prone to obesity than those on the Northern and Eastern provinces [4].

An attempt has been made in this study to determine the prevalence of obesity ( $\geq 30$ BMI - body mass index) among the selected type II diabetes mellitus subjects.

\author{
*Corresponding Author: \\ Vedavalli Sachithananthan, \\ Faculty of Public health, College of Applied Medical Sciences, King Khalid University, Abha, Saudi Arabia. \\ Tel: 00966553243155 \\ E-mail: dr_vedavalli@yahoo.com \\ Received: October 09, 2017 \\ Accepted: November 20, 2017
}

Published: November 22, 2017

Citation: Sachithananthan V. A Study on the Prevalence of Obesity in Type II Diabetes Mellitus among Female Adults Aged 20-50 Years Attending Abha and Khamis Mushayat Diabetic Centres in Saudi Arabia. Int J Food Sci Nutr Diet. 2017;6(4):363-365. doi: http://dx.doi.org/10.19070/2326-3350-1700064

Copyright: Sachithananthan $V^{\mathscr{O}}$ 2017. This is an open-access article distributed under the terms of the Creative Commons Attribution License, which permits unrestricted use, distri bution and reproduction in any medium, provided the original author and source are credited. 


\section{Materials and Methods}

1000 female subjects with type II diabetes mellitus were selected randomly for the study in the age group of 30-50 years from the Diabetic centres in Abha and Khamis Mushayat cities. An interview was conducted to collect the required socio economic background data. Also height and weight were measured to calculate the BMI (Body mass index). Waist and hip circumferences and fasting and random blood sugar levels were measured by standard procedures. The collected data were coded and uploaded on SPSS 20 for analysis.

\section{Results}

\section{Family Background of the Selected Subjects}

The socio economic background of the selected subjects is presented in the following tables:

Table 1. Area of residence of the selected subjects.

\begin{tabular}{|c|c|c|}
\hline & & Valid Percent \\
\hline \multirow{4}{*}{ Valid } & Khamis Mushayat & 49.7 \\
\cline { 2 - 3 } & Abha & 50.3 \\
\cline { 2 - 3 } & Total & 100 \\
\hline
\end{tabular}

Almost an equal number of subjects (around 50\%) were selected from Abha and Khamis Mushayat Diabetic centres in Saudi Arabia, due to ease of accessibility.

Table 2. Education of the study subjects.

\begin{tabular}{|c|c|c|}
\hline & & Valid Percent \\
\hline \multirow{4}{*}{ Valid } & No & 53.6 \\
\cline { 2 - 3 } & Yes & 46.4 \\
\cline { 2 - 3 } & Total & 100 \\
\hline
\end{tabular}

A majority of the subjects were not educated (53.6\%), whereas the remaining $46.4 \%$ were educated.
Table 3. Occupation of the study subjects.

\begin{tabular}{|c|c|c|}
\hline & & Valid Percent \\
\hline \multirow{4}{*}{ Valid } & no & 33.1 \\
\cline { 2 - 3 } & yes & 66.9 \\
\cline { 2 - 3 } & Total & 100 \\
\hline
\end{tabular}

A majority of the subjects did not have an occupation (86.1\%), whereas the remaining $13.9 \%$ had an occupation.

Table 4. Members of the family and ancestors if diabetic.

\begin{tabular}{|c|c|c|c|c|}
\hline \multicolumn{2}{|c|}{} & Percent & $\begin{array}{c}\text { Valid } \\
\text { Percent }\end{array}$ & $\begin{array}{c}\text { Cumulative } \\
\text { Percent }\end{array}$ \\
\hline \multirow{3}{*}{ Valid } & No & 33.1 & 33.1 & 33.1 \\
\cline { 2 - 5 } & Yes & 66.9 & 66.9 & 100.00 \\
\cline { 2 - 5 } & Total & 100.00 & 100.00 & \\
\hline
\end{tabular}

A majority of the family members and ancestors had diabetes $(66.9 \%)$, whereas the remaining $33.1 \%$ were not diabetic.

\section{BMI Status of the Study Subjects}

Table 5. BMI status of the study subjects.

\begin{tabular}{|c|c|c|}
\hline & & Valid Percent \\
\hline \multirow{4}{*}{ Valid } & Normal weight & 5.3 \\
\cline { 2 - 3 } & Overweight & 25.2 \\
\cline { 2 - 3 } & Grade 1 obesity & 31.1 \\
\cline { 2 - 3 } & Grade 2 obesity & 29.8 \\
\cline { 2 - 3 } & morbid obesity & 8.6 \\
\cline { 2 - 3 } & Total & 100.00 \\
\hline
\end{tabular}

A majority of the study subjects were in Grade I obesity (31.1\%$\mathrm{BMI}=30-34.9)$ and Grade II (29.8\% - BMI = $35-39.9)$ categories. Twenty-five percent of the subjects were overweight (25-29.9

Figure 1. BMI Status of the Study Subjects.

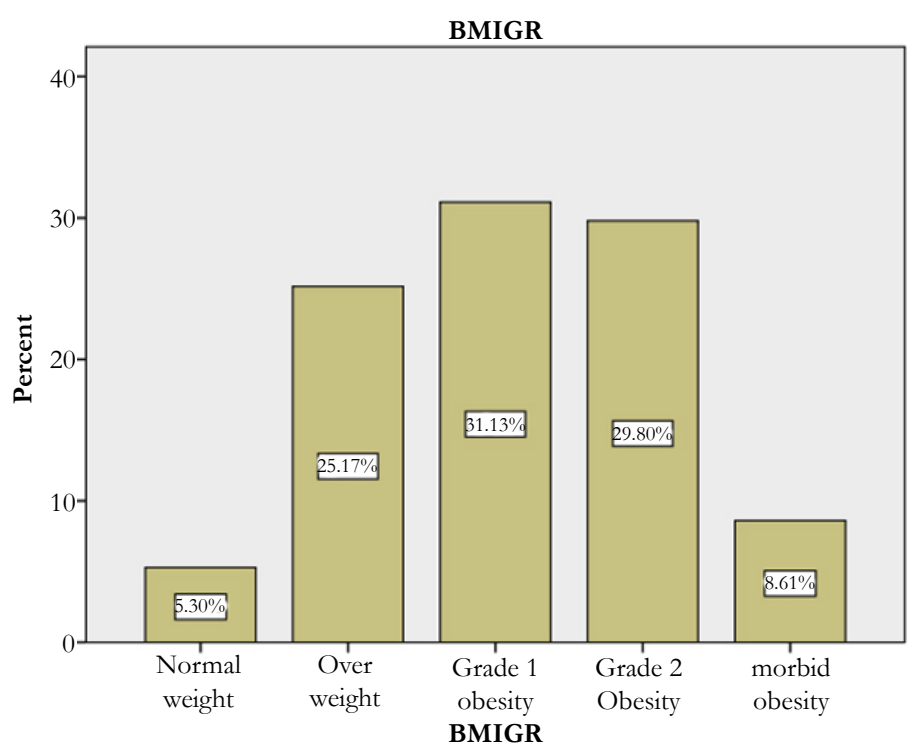


Table 6. Other anthropometric and biochemical parameters of the selected subjects.

\begin{tabular}{|c|c|c|c|c|}
\hline Parameters & Minimum & Maximum & Mean & Std. Deviation \\
\hline Height $(\mathrm{cm})$ & 140.00 & 170.00 & 156.8146 & 5.00720 \\
\hline Weight $(\mathrm{kg})$ & 55.00 & 115.00 & 81.3974 & 13.04713 \\
\hline Waist circumference $(\mathrm{cm})$ & 77.00 & 140.00 & 103.8675 & 13.58267 \\
\hline Hip circumference $(\mathrm{cm})$ & 85.00 & 150.00 & 115.4437 & 12.36535 \\
\hline Fasting blood sugar $(\mathrm{mg} / \mathrm{dl})$ & 70.00 & 305.00 & 137.2185 & 48.85132 \\
\hline Random blood sugar $(\mathrm{mg} / \mathrm{dl})$ & 100.00 & 460.00 & 251.4172 & 89.92837 \\
\hline
\end{tabular}

BMI). Only $5.3 \%$ of the subjects were of normal weight BMI. Around $8.6 \%$ of the subjects had morbid obesity ( $\geq 40 \mathrm{BMI}$ ). Totally the prevalence of obesity in type II diabetic mellitus subjects was $69.5 \%$.

\section{Other Anthropometric and Biochemical Parameters}

The mean of all the above parameters such as mean BMI (33), waist circumference $(103.86 \mathrm{~cm})$, hip circumference $(115.44 \mathrm{~cm})$, were well above the standards thus indicating obesity and central obesity. Also fasting $(137.2 \mathrm{mg} / \mathrm{dl})$ and random $(251.42 \mathrm{mg} / \mathrm{dl})$ blood sugar levels were also well above the diagnostic criteria for diabetes mellitus. Hence it can be stated that the subjects did not have controlled blood sugar levels. The complications of diabetes mellitus will set in, if hyperglycemia is not controlled. Also the central obesity parameters show the prevalence of central obesity to be very high in type II diabetes mellitus patients which prones towards more severe complications.

\section{Discussion}

The socioeconomic background did not correlate with the BMI and other selected anthropometric (waist and hip circumference) and biochemical parameters such as fasting and random blood sugar levels. This may be due to the fact that the subjects were already diabetic and suffering from severe hyperglycemia.

With regards to the BMI status of the subjects, a majority of the subjects were in the Grade II and Grade I obesity range indicating high prevalence rate of obesity in the diabetes mellitus subjects. Totally the prevalence of obesity in the present study in type II diabetes mellitus subjects was $69.5 \%$. This is somewhat higher than the prevalence of obesity in adults, adolescents, and children in the Middle Eastern/North African region, which is amongst the highest worldwide ranging between $2 \%-55 \%$ in adult females and $1 \%-30 \%$ in adult males while the prevalence in adolescents and children range from 5\%-14\% [5]. An estimate from the $\mathrm{Na}$ - tional Center for Health Statistics (NHANES III) reported that $78.5 \%$ of diabetics were overweight, and $45.7 \%$ were obese [6].

This scenario has to be managed both by the subjects and the dietitians,' because uncontrolled type II diabetes mellitus may lead to severe complications and early death. In order to fight this disease, efforts from the dietitians, physicians and family members should be towards counseling the patients on the importance of maintaining normal weight and having good physical activity during the day, in addition to exercise and diet.

\section{Conclusion}

With regards to the BMI status of the subjects, a majority of the subjects were in the Grade II and Grade I obesity range indicating high prevalence rate of obesity in the diabetes mellitus subjects. Steps should be taken by the dietitians' by constant counseling to prevent and eradicate obesity and thereby reduce the severity and complications of type II diabetes mellitus in the long run.

\section{References}

[1]. Type 2 Diabetes. April, 2017. Available online at http://www.diabetes.co.uk/ type2-diabetes.html.

[2]. Neel JV. Diabetes mellitus: a "thrifty" genotype rendered detrimental by "progress" ?. Am J Hum Genet. 1962 Dec;14(4):353-62. PubMed Central PMCID: PMC1932342.

[3]. Al-Nozha MM, Al-Maatouq MA, Al-Mazrou YY, Al-Harthi SS, Arafah MR, Khalil MZ, et al., "Diabetes mellitus in Saudi Arabia". Saudi Med J. 25(11):1603-1610. PubMed PMID: 15573186.

[4]. Al-Othaimeen AI, Al-Nozha M, Osman AK. Obesity: an emerging problem in Saudi Arabia. Analysis of data from the national nutrition survey. East Mediterr Health J. 2007 Apr;13(2):441-448. PubMed PMID: 17684864.

[5]. Nasreddine L, Mehio-Sibai A, Mrayati M, Adra N, Hwalla N. Adolescent obesity in Syria: prevalence and associated factors. Child Care Health Dev. 2010 May;36(3):404-413. PubMed PMID: 19931497.

[6]. Freemantle N, Holmes J, Hockey A, Kumar S. How strong is the association between abdominal obesity and the incidence of type 2 diabetes? Int J clin pract. 2008 Sep;62(9):1391-96. PubMed Cemtral PMCID: PMC2658023. 